\title{
A MINI-REVIEW OF ELECTROANALYTICAL METHODS FOR PESTICIDES QUANTIFICATION
}

\author{
SONJA JEVTIĆ ${ }^{*}$, DALIBOR STANKOVIĆ ${ }^{2}$, ANJA JOKIĆ ${ }^{1}$, BRANKA PETKOVIĆ ${ }^{1}$ \\ ${ }^{1}$ Faculty of Sciences, University of Priština, Kosovska Mitrovica, Serbia \\ ${ }^{2}$ The Vinča Institute of Nuclear Sciences, University of Belgrade, Belgrade, Serbia.
}

\begin{abstract}
This review paper shows the progress made in the last five years in electrochemical methods applied for the purpose of detection and quantification of pesticides - nowadays the most serious pollutants of the environment. Most pesticides can be successfully analyzed by chromatographic techniques, but because of high prices and immobility of the apparatus, the complexity of the method and the necessary special preparation of the samples, electrochemical methods have been recognized as an excellent alternative solution due to their advantages in speed, economy, simplicity and no exhaustive sample preparation. As the main limitation for use of this methods is electrochemical inactivity of many pesticides, this paper gives the essence of all elctroanalytical methods for pesticide quantification applied in last period, with an overview of the electrode materials and modifiers applied in a purpose to enhance analytical procedures application and characteristics of electrochemical sensors.
\end{abstract}

Keywords: Electroanalytical methods, Techniques, Pesticides quantification, Electrode modifiers.

\section{INTRODUCTION}

Nowadays, agricultural production has become unimaginable without the use of a variety of compounds that serve to increase the yield of the targeted plant culture, destroying weeds (herbicides), insects (insecticides) and fungus (fungicides). All these substances are covered by a common name - pesticides. Their significance in this area is borne out by the fact that the yield of agricultural crops would be about 50\% smaller without the use of some of the pesticides, which would be a big problem, since the number of human population on a global level is increasing - only during the 20th century the population number rose from 1.65 billion to 6 billion ("The World at Six Billion"). And not only through agriculture, but also in other fields in everyday life, the use of pesticides raises the quality of our lives to a higher level (Damales, 2009). But, this application of pesticides has its price. Namely, the relationship between exposure to pesticides and many diseases has been established: Pakiston's disease, amyotrophic lateral sclerosis, diabetes, and numerous cancers. They are also the cause of respiratory diseases, nervous disorders, depression, hearing disorders, hepatitis, hormonal disorders, and so on. They remain long after use in soil and damage wild and domestic animals, birds and useful insects (Sanford et al., 2015; Andersson et al., 2014).

Evidently, it is essential to quickly, easily, efficiently, precisely and accurately determine the presence of pesticides in samples of any type. The most commonly used separation techniques are chromatography (gas (GC) and liquid (LC)) and mass spectrometry (MS). High performance liquid chromatography (HPLC) with mass or UV detection can

\footnotetext{
* Corresponding author: jevticsonja88@gmail.com

determine a large number of pesticides with fulfilment of almost all the above conditions. Gas chromatography is used in combination with different detectors but is limited to volatile substances. Non-volatile substances can be converted into volatile derivatives and then detected and quantyfied by this technique. Another solution for those pesticides is their determination by the HPLC technique, but it should be noted that commercial detectors are limited in terms of selectivity and sensitivity. In addition, these techniques require a costly, nonmobile apparatus, special training for handling and interpreting results, as well as a special exhaustive sample preparation (Liang et al., 2014; Navaratne \& Priyantha 2011).

The ideal method for determining pesticides is still being sought. Electrochemical methods have great predispositions in this field because they not only provide information on the quantitative content of pesticides, but also on the mechanisms of their oxidation and reduction, as well as on the possible products of decomposition. In addition, the equipment is cheaper and mobile and the measurement process is precise, accurate and fast, especially if it is performed on an unmodified electrode $(\mathrm{Ni}$ et al., 2014.). The disadvantages of unmodified electrodes can be overcome by modifying or coating the surface of the electrode with materials of different performances, which, if we use imagination, provides an unlimited number of possibilities.

Electrochemical methods and electrodynamics used in recent times for the determination of pesticides in real samples will be discussed in this review paper. Certainly, a prerequisite for electrochemical determination of all organic substances, as well as pesticides, is the presence of a group in a molecule that is electrochemically active in the working range of the selected 
electrode. For example whether pesticides from the organochloride group can be determined electrochemically or not, depends on whether chlorine atoms can be separated from the rest of the structure. As their solubility in water is not satisfactory, determination of those compounds is performed in micellar water, usually by the differential pulse technique or by adsorptive stripping voltammetry (Bakirhan et al., 2018.). 38\% of pesticides used on the global level are organophosphorus pesticides (Gothwal et al., 2014.) that contain a simple or double bond of bonded phosphorus and oxygen atoms, or phosphorus and sulfur, which is associated with their electrochemical activity. Triazines, compounds with a herbicidal effect, have two groups: s-triazine and asymmetric triazine with heterocyclic ring on which a reduction reaction occurs by protonation on nitrogen atom. Nitro pesticides, highly toxic compounds, are electrochemically active owing to the nitro group which usually passes into the form of hydroxylamine. Unlike them, sulphonylurea pesticides are low toxicity compounds rarely determined by electroanalytical methods. Bipyridinium pesticides are not all electrochemically active, and those that are, get reduced to nitro-monocations (Bakirhan et al., 2018.).

Next sections in this paper are dedicated to describing a purpose and advantages of electrochemical techniques, electrode materials and modifiers used in pesticide analysis. The summary of the basic data for pesticides electrochemically determined in the last five years are given in Table 1. Besides quantification methods and electrode modifiers, the table also contains data about used/optimal experimental conditions, method validation parameters and applied real samples.

\section{ELECTROCHEMICAL TECHNIQUES IN PESTICIDE ANALYSIS}

Electroanalytical determinations of pesticides usually were performed by pulse voltammetric techniques and amperometry, but sometimes cyclic voltammetry was used in this purpose (Figure 1).

\section{Cyclic Voltammetry}

Cyclic voltammetry (CV) is unavoidable in the electrochemical studies of not only pesticides, but also in many other electrochemically active organic and metal organic compounds. Although surpassed in the field of quantitative measurements, it remains an indispensable instrument for monitoring the oxidation and reduction mechanisms of the analyte as well as an indisputable indicator for possible intermediates (Skoog et al., 1997.). Cyclic voltammogram gives five important data: cathode and anode peaks corresponding to cathode and anode currents and the value of half potential. Those data, as well as their mutual relations, are parameters for determining the type of reaction on the electrode (reversible, irreversible, or quasi reversible) (Tonle \& Ngameni, 2011.).
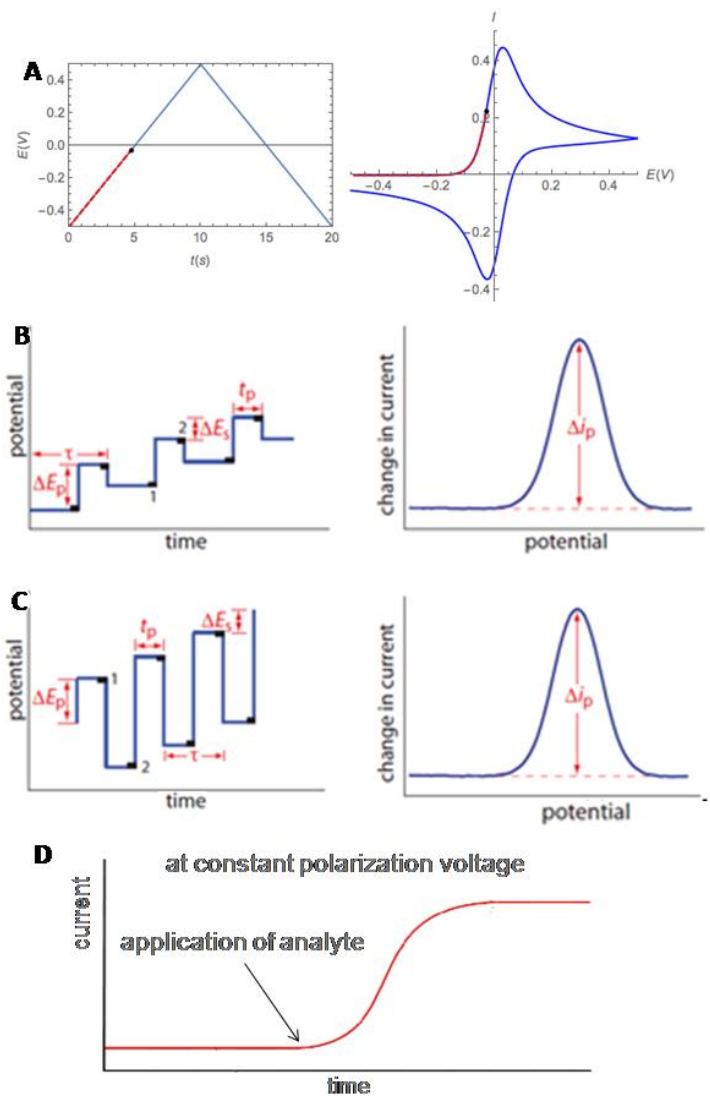

Fig. 1. Electrochemical techniques - parameters and characteristic voltammograms: A) cyclic voltammetry, B) differential pulse voltammetry, C) square-wave voltammetry and D) amperometry.

Any electrochemical pesticide investigation reported recently has been initiated by cyclic voltammetry. This is the perfect technique for confirming the success of the modification, as well as for finding the optimal conditions, the amount and the ratio of the modifiers. The concrete application of almost all electrodes modified in various ways is preceded by the precise recording of cyclic voltammograms. Thus, Olivera et al., 2014, using CV method came to optimum modifiers of the glassy carbon electrode. They combined two enzymes, laccase and tyrosinase, then enzymes with chitosan, and then enzymes, cytosan and gold nanoparticles. The last combination is due to the strongest current taken as optimal for the SWV quantification of ziram, carbaryl, propoxur and formethane pesticides. By studying the electrochemical behavior of relatively new pesticides, the first electrochemical data are obtained by cyclic voltammetry, using various electrodes and supporting electrolytes. Thus, the assumption that the herbicide pentoxamide can be determined electrochemically was precisely examined by Jevtić et al., 2018b., by CVs recorded in a potential range of -1.5 to $2 \mathrm{~V}$ in different $\mathrm{pH}$ values of Britton-Robinson buffer and based on a clear oxidation peak at $+1.45 \mathrm{~V}$. The quantification of this pesticide was performed with more suitable 
square-wave voltammetric technique. Selva et al., 2017. showed that it is possible to determine pesticides from two groups (carbamates and organophosphates) in different concentrations precisely by cyclic voltammetry, and if more sensitivity is required, they proposed pulse methods.

\section{Pulse methods}

The key problem of voltammetric measurements is the insufficiently low detection limit as a direct consequence of the occurrence of a capacitive current. The solution to this problem was given by Barker and Jenkin in 1952. by introducing pulse methods among electrochemical analysis techniques. The essence of these methods is the same - electrode processes on working electrodes are triggered by pulse potential changes with a constant or increasing amplitude, which, at the end of the pulse duration, results in the measurement of the faradaic current, while at the same time the capacitive current almost completely disappears. The result of the measurement is the current peak whose height is directly proportional to the concentration of the analyte (Tonle \& Ngameni, 2011.). The most commonly applicable are the differential pulse voltammetry (DPV) and square-wave voltammetry (SWV). In SWV, a potential in the form of symmetric square impulses is applied to the working electrode, and the current is recorded at two points - one at the end of the pulse, which causes a high value of the oxidative current, and one at the end of the pulse responsible for the jump in the reduction current. The resulting voltammogram is bellshaped and its intensity is proportional to the concentration of the analyte. In DPV, the stimulating signal consists of small stepped pulses of constant potential, and the current is, as in the case of SWV, recorded in two points. How effective they are in the field of quantification of the target analyte shows the fact that the electrochemical determination of $85 \%$ of pesticides, after the first electrochemical data obtained by cyclic voltammetry, is quantified precisely by these methods. Costa et al., 2017. applied both types in the detection of methomyl pesticides, as was done by Jevtić et al., 2018a. in the detection of bentazone. In both cases, a small but significant advantage is given to DPV, but SWV is faster technique, and as it can be seen from Table 1, SWV is chosen for determination of pesticides in many cases. For the determination of three pesticides of chlorpropham, thiodicarb and aldicarb in soil, Babu et al. 2014. successfully applied DPV in combination with adsorptive stripping voltammetry.

\section{Amperometry}

Amperometry is based on the measurement of current that occurs as a result of the reduction or oxidation of electroactive species on the electrode (Mostafa, 2010.). The determination of almost all pesticides (in the target period of this review) by this method is in fact based on reducing the flow of current (inhibition) resulting from the decrease in the activity of acetylcholinesterase enzymes due to the action of very toxic pesticides from the group of organophosphates, rarely carbamates. The idea for this type of biosensor has came from the fact that pesticides (especially organophosphate type) are strong nurotoxins that act by esterifying a hydroxyl group of serine in acetylcholinesterase which is responsible for transmitting nerve impulses over the synapse. (Hassani et al., 2016.). Mogha et al., 2016. using a zirconium oxide electrode and a reduced graphene oxide in combination with immobilized acetylcholinesterase, quantified insecticide chlorpyrifos with the highest sensitivity in relation to the reported cases up to $10^{-13} \mathrm{M}$. The same insecticide, about one year earlier, was determined on a glassy carbon electrode modified by a combination of acetylcholinesterase, iron-oxide nanoparticles, and poly (indole5-carboxylic acid) but with significantly less sensitivity (see Table 1). The insecticide of organophosphate type, methylparation was successfully amperometrically determined in vegetables and fruits by using an electrode that combines silvergraphene nanoribbons film and screen printed carbon electrode (Govindasamy et al., 2017.).

\section{Potentiometry}

Potentiometry involves measuring potential differences between the two electrodes, the indicator and the reference electrodes or between the two indicator electrodes separated by a semiconductor membrane, while there is no significant current flow between them. (Mostafa, 2010.). Potentiometry has not been particularly popular in the field of pesticide quantification lately, and this statement proves, as far as we can found, only one paper of this type reported in the last five years. Namely, Mashuni et al., 2016. quantified the diazinon - insecticide from the group of organophosphates with this method, using a golden electrode modified with an acetylcholinesterase immobilized in glutaraldehyde and cellulose acetate. After determining the optimal ratio of glutaraldehyde $(25 \%)$ and cellulose acetate (15\%), diazinone is quantified to a detection limit of $10^{-6} \mathrm{ppm}$ where a stable potentiometric response is achieved in $5 \mathrm{~min}$.

\section{ELECTRODE MATERIALS}

The effectiveness of electrochemical determinations depends to a large extent on the choice of the appropriate electrode material. An important criterion for this is the low background current, wide potential window, reproducibility, stability, and electron transfer kinetics. Adsorption is also an important factor because impurities or reaction products can deactivate the electrode, which would further require the electrode renewal (Uslu \& Ozkan, 2007.).

\section{Glassy carbon electrode}

Although used for the first time in 1967, this electrode does not lose its significance, which is not surprising because it has a wide potential "window", it is solid, the surface is renewable and impermeable to gases, and it can be applied in negative 
potentials and in the acidic environment (Sanghavi et al., 2015.). It is easily built up, polished and it is functional in the most commonly used solvents. The carbon atoms are $\mathrm{sp}^{2}$ hybridized and arranged in layers as in the graphite, but more densely distributed and impregnation procedures are not required. It was found that this electrode material is significantly less oxidized in oxygen, carbon dioxide or water oxygen, than other carbon materials (Uslu \& Ozkan, 2007.). Based on the data from the table, it could be concluded that the glassy carbon electrode (GC) is applied in almost $50 \%$ of the papers in the field of electrochemical determination of pesticides published in the last five years. It is very suitable for modification, and in most cases GC is modified, which results in better sensitivity and selectivity of determination. The only case where this electrode is not modified is the determination of pesticides of propoxur, paration, methyl parathion, carbofuran and carbaryl. The data about the detection limit and the linear potential is not given, since the purpose of the paper was to show that it is possible to separate pesticides from two classes of compounds (organophosphates and carbamates) on the basis of the fact that pesticides from the carbamate group have a peak at $+1.4 \mathrm{~V}$, and those of the organophosphate group at $-0.6 \mathrm{~V}$ (Selva et al., 2017.). The applied modifiers are very diverse, ranging from those based on carbon nanoparticles (Teadoum et al., 2016; Xu F. et al., 2017; Xu G. et al., 2017; Irandoust \& Haghighi 2016; Yao et al., 2014; Feng et al., 2015; Yang et al., 2015; Li et al., 2014;), to combinations of various types of nanoparticles with biocomponents (Cai et al., 2014; Chauhan et al., 2015; Guler et al., 2017; Zhang et al., 2015).

\section{Carbon paste electrode}

Carbon paste electrodes are essentially a mixture of graphite powder and water insoluble organic fluids, which after careful mixing is packaged in a suitable inert container with electrical contact on one side. The greatest advantage of this type of carbon electrode is its surface reproducibility as an important precondition for repeatability of results and low background currents. Its electrochemical properties depend on the applied organic fluids whose quantity must be selected so that it is enough to maintain the structure of the electrode, but in limited content, because the transfer of the electron would be disturbed and the background currents increased. This electrode is not selective, but is considered to be the most suitable for modifications, which indicates a number of possibilities used (Uslu \& Ozkan, 2007.). For the determination of pesticides from the group of carbamates (chlorpropham, thiodicarb and aldicarb) in the soil, Babu et al., 2014. made an electrode of this type by mixing multi-walled nanotubes and castrol oils and packing the resulting mass into a Teflon tube. The achieved detection limit is about $1.09 \times 10^{-7} \mathrm{M}$ for each of mentioned pesticides. Pesticides carbaryl, propoxur formetanate and zyram were determined in citrus fruits with graphene-doped carbon paste electrode in combination with two enzymes, cytosan and gold nanoparticles.
This determination was advantageous in relation to the usual chromatographic determination in terms of speed and simplicity (Oliveira et al., 2014.).

\section{Screen printed carbon electrode}

A pesticide from the organophosphate group, methyl parathion is determined in fruit and plants using a modified screen printed electrode. The modification was done using silver nanoparticles supported by graphene nanotubes. The detection limit is $0.5 \mathrm{nM}$ (Govindasamy et al., 2017.).

Two papers report a molecularly imprinted polymer electrode in combination with multidisciplinary nanoparticles and carbon monoxide for the detection of dichlorane. (Khadem et al., 2016; Shahtaheri et al., 2017.). Molecular imprinting is a technique in which a cocktail of functional monomers have reversible interaction with the target molecule using noncovalent forces. The complex is then networked and polymerized in the casting process, leaving behind a polymer with recognition sites complementary to the target molecule both in shape and functionality. Each such site consists of an induced molecular "memory" capable of selective binding to the chosen target sites (Jokanović, 2012.).

\section{Gold electrodes}

The limitation of the application of the gold electrode in the cathodic regions results in limitations in the analysis of the reducing substances. This problem is substantially resolved by the application of gold microelectrodes and the application of various types of modifiers (Fischer et al, 2011.). On the gold electrode Lin et al., 2017. applied a combination of anti atrazine and gold nanoparticles for modification, which significantly increased the surface area of the working electrode and under optimum conditions allowed detection of atrazine insecticide with a limit of $0.016 \mathrm{ng} / \mathrm{mL}$. In the paper reported recently, the potentiometric biosensor was used, and the gold electrode is presented as carrier for acetylcholinesterase immobilized in glyceraldehyde and cellulose acetate. The insecticide diazinon from the organophosphate group was detected with detection limit of $10^{-6} \mathrm{ppm}$ (Mashuni et al., 2016.). The gold electrode was also used by Ribeiro et al., 2014. as the basis for a modification with the laccase enzyme and gold nanoparticles to determine the pesticide formetanate hydrochloride with a good sensitivity of the magnitude of $10^{-8} \mathrm{M}$.

\section{Boron-doped diamond electrodes}

As a working electrode, the boron-doped diamond electrode possesses some remarkable features. Its exceptional performances confirms the fact that many pesticides were determined by this unmodified electrode, and modification was carried out in only two cases (carbaryl and paraquat) by graphene (Pop et al., 2017.). Compared to conventional carbon and metal electrodes, the boron-doped diamond electrode (BDDE) is significantly more inert and chemically stable, which makes it suitable for use in extreme chemical environments such as acidic solutions. 
Table 1. List of pesticides with the most important data, determined electrochemically in period from 2014. to 2018.

\begin{tabular}{|c|c|c|c|c|c|c|c|c|c|c|}
\hline 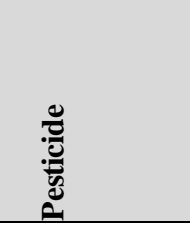 & $\overbrace{\Leftrightarrow}$ & 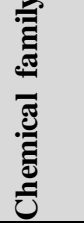 & 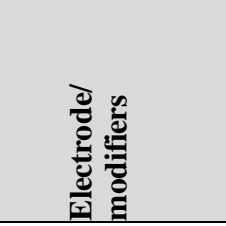 & 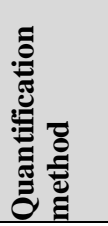 & 竞 & 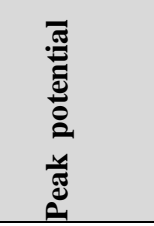 & 苑 & 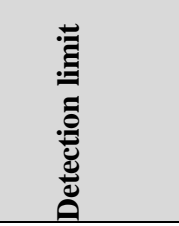 & 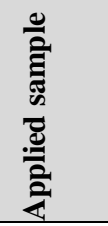 & $\stackrel{\ddot{\Xi}}{\simeq}$ \\
\hline Aldicarb & I & $\mathrm{CB}$ & MWCNT-PE & $\begin{array}{l}\text { DPV } \\
\text { and } \\
\text { AdSV }\end{array}$ & $\begin{array}{c}\mathrm{pH} 4 \\
\text { boric acid/ } \\
\text { citric acid/ } \\
\text { trisodium } \\
\text { ortho } \\
\text { phosphate }\end{array}$ & $\begin{array}{c}-0.45 \mathrm{~V} \mathrm{vs} \\
\mathrm{Ag} / \mathrm{AgCl}\end{array}$ & $10^{-5}$ to $10^{-10} \mathrm{M}$ & $1.09 \times 10^{-7} \mathrm{M}$ & soil & $\begin{array}{l}\text { Babu } \\
\text { et al., } \\
2014 .\end{array}$ \\
\hline Atrazine & $\mathrm{H}$ & $\mathrm{TZ}$ & $\begin{array}{l}\text { anty-atrazine- } \\
\text { AuNPs/GE }\end{array}$ & DPV & $\begin{array}{c}\text { pH } 5 \\
\text { phosphate } \\
\text { buffer }\end{array}$ & $\begin{array}{c}0.21 \mathrm{~V} \text { vs } \\
\mathrm{SCE}\end{array}$ & $\begin{array}{l}0.05 \text { to } 0.5 \\
\mathrm{ng} / \mathrm{mL}\end{array}$ & $\begin{array}{l}0.016 \\
\mathrm{ng} / \mathrm{mL}\end{array}$ & water & $\begin{array}{l}\text { Liu } \\
\text { et al., } \\
2014 .\end{array}$ \\
\hline Azametiphos & I & OPs & BDDE & SWV & $\begin{array}{c}\mathrm{pH} 0 \\
1 \mathrm{M} \text { nitric } \\
\text { acid }\end{array}$ & $\begin{array}{l}1.7 \mathrm{~V} \text { vs } \\
\mathrm{Ag} / \mathrm{AgCl}\end{array}$ & 2 to $100 \mu \mathrm{M}$ & $0.45 \mu \mathrm{M}$ & $\begin{array}{l}\text { river } \\
\text { water }\end{array}$ & $\begin{array}{c}\text { Vukojev } \\
\text { ić et al., } \\
2018 .\end{array}$ \\
\hline Bentazone & $\mathrm{H}$ & TDZ & BDDE & $\begin{array}{l}\text { DPV } \\
\text { and } \\
\text { SWV }\end{array}$ & $\begin{array}{c}\text { pH } 4 \\
\text { Britton- } \\
\text { Robinson } \\
\text { buffer }\end{array}$ & $\begin{array}{l}1.0 \mathrm{~V} \mathrm{vs} \\
\mathrm{Ag} / \mathrm{AgCl}\end{array}$ & 2 to $100 \mu \mathrm{M}$ & $0.5 \mu \mathrm{M}$ & $\begin{array}{l}\text { river } \\
\text { water }\end{array}$ & $\begin{array}{l}\text { Jevtić } \\
\text { et. al., } \\
2018 .\end{array}$ \\
\hline Carbaryl & I & $\mathrm{CB}$ & $\begin{array}{l}\text { LACC-TYR- } \\
\text { AuNPs-CS/ } \\
\text { GPE } \\
\text { BDDE/GR } \\
\text { GCE }\end{array}$ & $\begin{array}{l}\text { SWV } \\
\text { DPV }\end{array}$ & $\begin{array}{c}\text { pH 5.5 } \\
\text { Britton-- } \\
\text { Robinson } \\
\text { buffer } \\
\text { pH } 5.6 \\
\text { acetate } \\
\text { buffer } \\
\text { pH } 7 \\
\text { phosphate } \\
\text { buffer }\end{array}$ & $\begin{array}{l}-0.6 \mathrm{~V} \mathrm{vs} \\
\mathrm{Ag} / \mathrm{AgCl} \\
1.45 \mathrm{~V} \text { vs. } \\
\mathrm{SCE} \\
1.4 \mathrm{~V} \mathrm{vs} \\
\mathrm{Ag} / \mathrm{AgCl}\end{array}$ & $\begin{array}{l}9.90 \times 10^{-8} \text { to } \\
2.91 \times 10^{-6} \mathrm{M} \\
1 \text { to } 6 \mu \mathrm{M}\end{array}$ & $\begin{array}{l}1.98 \times 10^{-8} \mathrm{M} \\
0.07 \mu \mathrm{M}\end{array}$ & $\begin{array}{l}\text { citrus } \\
\text { fruits } \\
\text { apple } \\
\text { juice }\end{array}$ & $\begin{array}{l}\text { Oliveira } \\
\text { et al., } \\
2014 . \\
\\
\text { Pop } \\
\text { et al., } \\
2017 . \\
\\
\text { Selva } \\
\text { et al., } \\
2017 .\end{array}$ \\
\hline Carbendazim & $\mathrm{F}$ & BI & $\begin{array}{l}\text { Fullerene/MWC } \\
\text { NT/ } \\
\text { NA/GCE }\end{array}$ & SWV & $\begin{array}{l}\text { pH } 9 \\
\text { acetate } \\
\text { buffer }\end{array}$ & $\begin{array}{l}0.67 \mathrm{~V} \text { vs } \\
\mathrm{Ag} / \mathrm{AgCl}\end{array}$ & $\begin{array}{l}2.0 \times 10^{-8} \text { to } \\
3.5 \times 10^{-7} \mathrm{M}\end{array}$ & $\begin{array}{l}1.7 \times 10^{-8} \\
\mathrm{~mol} / \mathrm{L}\end{array}$ & soil & $\begin{array}{l}\text { Teadoum } \\
\text { et al., } \\
2016 .\end{array}$ \\
\hline Carbofuran & I & $\mathrm{CB}$ & $\begin{array}{l}\text { ITO/CoPc-AQ- } \\
\text { LB } \\
\text { AChE/CNS/ } \\
\text { GCE } \\
\text { GCE }\end{array}$ & 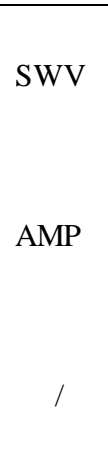 & $\begin{array}{c}\text { pH } 7 \\
\text { phosphate } \\
\text { buffer } \\
\text { pH } 7.5 \\
\text { phosphate } \\
\text { buffer } \\
\text { pH } 7 \\
\text { phosphate } \\
\text { buffer }\end{array}$ & $\begin{array}{l}1.4 \mathrm{~V} \mathrm{vs} \\
\mathrm{Ag} / \mathrm{AgCl}\end{array}$ & $\begin{array}{l}0.0397 \times 10^{-6} \\
\text { to } 2.82 \times 10^{-6} \\
\mathrm{M} \\
0.4 \text { to } 4.79 \\
\mu \mathrm{g} / \mathrm{L}\end{array}$ & $5.81 \times 10^{-7} \mathrm{M}$ & $\begin{array}{l}\text { water } \\
\text { lettuce } \\
\text { cabba } \\
\text { ge, } \\
\text { oilseed } \\
\text { water }\end{array}$ & $\begin{array}{l}\text { Ipek } \\
\text { et al. } \\
2014 . \\
\text { Cai } \\
\text { et al., } \\
2014 . \\
\text { Selva } \\
\text { et al., } \\
2017 .\end{array}$ \\
\hline
\end{tabular}




\begin{tabular}{|c|c|c|c|c|c|c|c|c|c|c|}
\hline 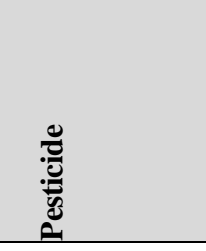 & 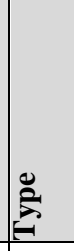 & 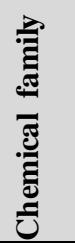 & 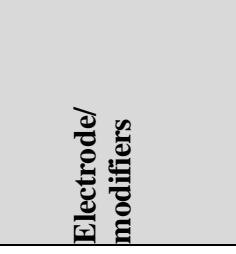 & 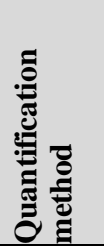 & 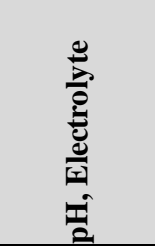 & 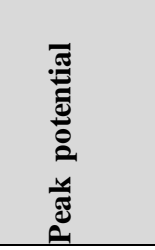 & 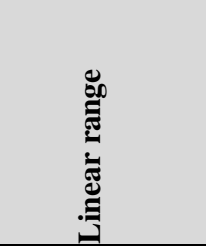 & 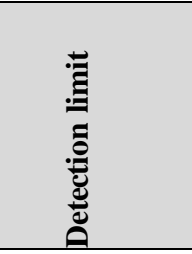 & 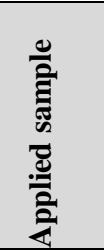 & 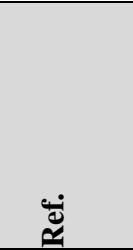 \\
\hline Chlorpropham & $\mathrm{H}$ & CB & MWCNT-PE & $\begin{array}{l}\text { DPV } \\
\text { and } \\
\text { AdSV }\end{array}$ & $\begin{array}{c}\text { pH } 4 \\
\text { boric acid/ } \\
\text { citric acid/ } \\
\text { trisodium } \\
\text { ortho } \\
\text { phosphate }\end{array}$ & $\begin{array}{l}-0.18 \mathrm{~V} \text { vs } \\
\mathrm{Ag} / \mathrm{AgCl}\end{array}$ & $10^{-5}$ to $10^{-10} \mathrm{M}$ & $1.09 \times 10^{-7} \mathrm{M}$ & soil & $\begin{array}{l}\text { Babu } \\
\text { et al., } \\
2014 .\end{array}$ \\
\hline \multirow{4}{*}{ Chlorpyrifos } & \multirow{4}{*}{ I } & \multirow{4}{*}{ OPs } & $\begin{array}{l}\mathrm{AChE} \\
\text { /Pin5COOH/ } \\
\mathrm{Fe}_{3} \mathrm{O}_{4} \mathrm{NP} / \mathrm{GCE} \\
\\
\mathrm{AChE} / \mathrm{ZrO}_{2} / \\
\mathrm{RGO}\end{array}$ & AMP & $\begin{array}{c}\text { pH } 7 \\
\text { phosphate } \\
\text { buffer } \\
\\
\text { pH } 7 \\
\text { phosphate } \\
\text { buffer }\end{array}$ & $\begin{array}{l}0.36 \mathrm{~V} \text { vs } \\
\mathrm{Ag} / \mathrm{AgCl}\end{array}$ & $\begin{array}{l}1.5 \text { to } 70 \mathrm{nM} \\
10^{-9} \text { to } 10^{-4} \mathrm{M}\end{array}$ & $\begin{array}{l}9.1 \mathrm{nM} \\
10^{-13} \mathrm{M}\end{array}$ & water & $\begin{array}{l}\text { Chauhan } \\
\text { et al., } \\
2015 . \\
\text { Mogha } \\
\text { et al., } \\
2016 .\end{array}$ \\
\hline & & & $\begin{array}{l}\mathrm{CuO} \text { NFs- } \\
\text { SWCNTs/GCE }\end{array}$ & DPV & $\begin{array}{c}\text { pH } 7 \\
\text { phosphate } \\
\text { buffer }\end{array}$ & $\begin{array}{r}-0.35 \mathrm{~V} \text { vs } \\
\mathrm{Ag} / \mathrm{AgCl}\end{array}$ & $\begin{array}{l}0.1 \text { to } 150 \\
\mathrm{ng} / \mathrm{L}\end{array}$ & $70 \mathrm{pg} / \mathrm{mL}$ & $\begin{array}{l}\text { apple } \\
\text { celery } \\
\text { cabba- } \\
\text { ge }\end{array}$ & $\begin{array}{l}\text { Xu G. } \\
\text { et al., } \\
2017 .\end{array}$ \\
\hline & & & $\begin{array}{l}\mathrm{NA} / \mathrm{AuNPs} / \mathrm{rGO} \\
-\mathrm{NH}_{2} / \\
\mathrm{AChE} / \mathrm{GCE}\end{array}$ & $\mathrm{CV}$ & $\begin{array}{c}\text { pH } 8 \\
\text { phosphate } \\
\text { buffer }\end{array}$ & $\begin{array}{l}0.7 \mathrm{~V} \text { vs } \\
\mathrm{Ag} / \mathrm{AgCl}\end{array}$ & $\begin{array}{l}0.021 \text { to } 0.122 \\
\mathrm{mg} / \mathrm{mL}\end{array}$ & $14 \mathrm{ng} / \mathrm{mL}$ & water & $\begin{array}{l}\text { Guler } \\
\text { et al., } \\
2017 .\end{array}$ \\
\hline & & & $\begin{array}{l}\text { FTO-AuNPs- } \\
\text { chl-Ab }\end{array}$ & DPV & $\begin{array}{c}\text { pH } 7.5 \\
\text { phosphate } \\
\text { buffer }\end{array}$ & $0.35 \mathrm{~V}$ & $1 \mathrm{fM}$ to $1 \mu \mathrm{M}$ & $10 \mathrm{fM}$ & $\begin{array}{l}\text { apple, } \\
\text { pome- } \\
\text { granae } \\
\text { cabba- } \\
\text { ge }\end{array}$ & $\begin{array}{l}\text { Gandhi } \\
\text { et al., } \\
2018 .\end{array}$ \\
\hline Clomazone & $\mathrm{H}$ & ISD & BDDE & SWV & $\begin{array}{c}\text { pH } 2 \\
\text { Britton- } \\
\text { Robinson } \\
\text { buffer }\end{array}$ & $\begin{array}{l}1.6 \mathrm{~V} \mathrm{vs} \\
\mathrm{Ag} / \mathrm{AgCl}\end{array}$ & 1 to $100 \mu \mathrm{M}$ & $0.21 \mu \mathrm{M}$ & $\begin{array}{l}\text { river } \\
\text { water }\end{array}$ & $\begin{array}{l}\text { Djurdjić } \\
\text { et. al., } \\
2018 .\end{array}$ \\
\hline Diazinon & I & OPs & $\begin{array}{l}\text { AchE/CA/GA/ } \\
\text { GE }\end{array}$ & POT & $\begin{array}{c}\text { pH } 8 \\
\text { phosphate } \\
\text { buffer }\end{array}$ & I & $10^{-6}$ to $1 \mathrm{ppm}$ & $10^{-6} \mathrm{ppm}$ & I & $\begin{array}{l}\text { Mashuni } \\
\text { et al., } \\
2016 .\end{array}$ \\
\hline & & & $\begin{array}{l}\text { MWCNTs/ } \\
\text { MIP/CPE }\end{array}$ & SWV & $\begin{array}{c}\text { pH } 8 \\
\text { phosphate } \\
\text { buffer }\end{array}$ & $\begin{array}{l}0.1 \mathrm{~V} \text { vs } \\
\mathrm{Ag} / \mathrm{AgCl}\end{array}$ & $\begin{array}{l}1 \times 10^{-6} \text { to } \\
1 \times 10^{-9} \mathrm{~mol} / \mathrm{L}\end{array}$ & $\begin{array}{l}4.8 \times 10^{-10} \\
\mathrm{~mol} / \mathrm{L}\end{array}$ & $\begin{array}{l}\text { urine } \\
\text { and } \\
\text { water }\end{array}$ & $\begin{array}{l}\text { Khadem } \\
\text { et al., } \\
2016 .\end{array}$ \\
\hline Dicloran & F & NA & $\begin{array}{l}\text { MWCNTs/MIP/ } \\
\text { CPE }\end{array}$ & SWV & $\begin{array}{c}\text { pH } 8 \\
\text { phosphate } \\
\text { buffer }\end{array}$ & $0.3 \mathrm{~V}$ & $\begin{array}{l}1 \times 10^{-6} \text { to } \\
1 \times 10^{-9} \mathrm{~mol} / \mathrm{L}\end{array}$ & $4.8 \times 10^{-10}$ & $\begin{array}{l}\text { water, } \\
\text { river } \\
\text { water } \\
\text { and } \\
\text { urine }\end{array}$ & $\begin{array}{l}\text { Shahtaheri } \\
\text { et al., } \\
2017 .\end{array}$ \\
\hline $\begin{array}{l}\text { Dimethylvi- } \\
\text { nphos }\end{array}$ & I & OPs & $\mathrm{RGO} / \mathrm{CS} / \mathrm{GCE}$ & SWV & $\begin{array}{c}\mathrm{pH} 6 \\
\text { Britton- } \\
\text { Robinson } \\
\text { buffer } \\
\end{array}$ & $\begin{array}{l}-0.38 \mathrm{~V} \text { vs } \\
\mathrm{Ag} / \mathrm{AgCl}\end{array}$ & $\begin{array}{l}0.05 \text { to } 30.0 \\
\mu \mathrm{g} / \mathrm{L}\end{array}$ & $0.036 \mathrm{mg} / \mathrm{L}$ & $\begin{array}{l}\text { river } \\
\text { water }\end{array}$ & $\begin{array}{l}\text { Prasad et } \\
\text { al., } \\
2015 .\end{array}$ \\
\hline Dinitramine & $\mathrm{H}$ & $\mathrm{NP}$ & MWCNT/GCE & SWV & $\begin{array}{c}\mathrm{pH} 2 \\
\text { Britton- } \\
\text { Robinson } \\
\text { buffer }\end{array}$ & $\begin{array}{l}-0.50 \mathrm{~V} \text { vs } \\
\mathrm{Ag} / \mathrm{AgCl}\end{array}$ & $\begin{array}{l}4.0 \times 10^{-8} \text { to } \\
1.4 \times 10^{-6} \mathrm{~mol} / \mathrm{L}\end{array}$ & $\begin{array}{l}0.8 \times 10^{-8} \\
\mathrm{~mol} / \mathrm{L}\end{array}$ & water & $\begin{array}{c}\text { Irandoust } \\
\& \\
\text { Haghighi } \\
2016 .\end{array}$ \\
\hline
\end{tabular}




\begin{tabular}{|c|c|c|c|c|c|c|c|c|c|c|}
\hline 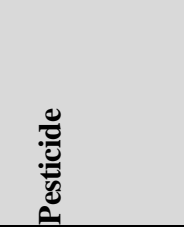 & $\sum_{i}$ & 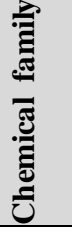 & 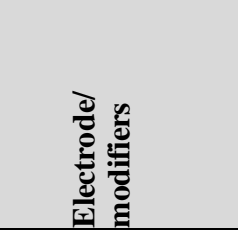 & 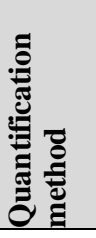 & 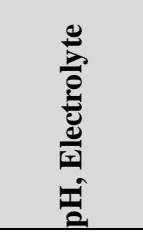 & 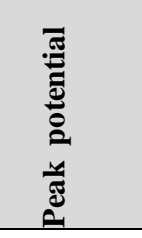 & 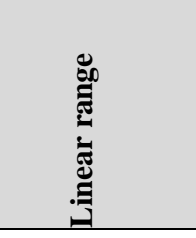 & 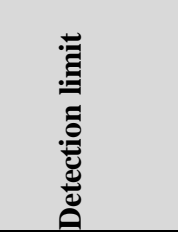 & 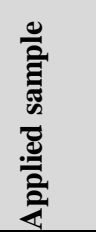 & $\stackrel{\ddot{\Xi}}{\ddot{\Xi}}$ \\
\hline Eserine & I & $\mathrm{CB}$ & $\begin{array}{l}\text { ITO/CoPc-AQ- } \\
\text { LB }\end{array}$ & SWV & $\begin{array}{c}\text { pH } 7 \\
\text { phosphate } \\
\text { buffer }\end{array}$ & $\begin{array}{l}-0.80 \mathrm{~V} \\
\text { vs SCE }\end{array}$ & $\begin{array}{l}0.00120 \times 10^{-6} \\
-1.42 \times 10^{-6} \mathrm{M}\end{array}$ & $6.40 \times 10^{-9} \mathrm{M}$ & water & $\begin{array}{l}\text { Ipek } \\
\text { et al., } \\
2014 .\end{array}$ \\
\hline Fenitrothion & I & OPs & $\begin{array}{l}\text { AchE/CNS/GCE } \\
\text { GCE }\end{array}$ & $\begin{array}{c}\text { AMP } \\
\text { / }\end{array}$ & $\begin{array}{c}\text { pH } 7.5 \\
\text { phosphate } \\
\text { buffer } \\
\text { pH } 7 \\
\text { phosphate } \\
\text { buffer }\end{array}$ & $\begin{array}{c}\text { / } \\
-0.6 \mathrm{~V} \text { vs } \\
\mathrm{Ag} / \mathrm{AgCl}\end{array}$ & $\begin{array}{l}6.26 \text { to } 125.31 \\
\mu \mathrm{g} / \mathrm{L} \\
\text { / }\end{array}$ & $\begin{array}{c}2.61 \mu \mathrm{g} / \mathrm{L} \\
/\end{array}$ & $\begin{array}{l}\text { lettuce } \\
\text { cabba- } \\
\text { ge, } \\
\text { oilseed } \\
\text { water }\end{array}$ & $\begin{array}{l}\text { Cai } \\
\text { et al., } \\
2014 . \\
\text { Selva } \\
\text { et al., } \\
2017 .\end{array}$ \\
\hline Formetanate & I & $\mathrm{CB}$ & $\begin{array}{l}\text { LACC-TYR- } \\
\text { AuNPs-CS/ } \\
\text { GPE } \\
\text { Lacc } \\
\text { /AuNPs/GE }\end{array}$ & SWV & $\begin{array}{l}\text { pH 5.5 } \\
\text { Britton- } \\
\text { Robinson } \\
\text { buffer } \\
\\
\text { pH 5 } \\
\text { Britton- } \\
\text { Robinson } \\
\text { buffer }\end{array}$ & $\begin{array}{l}0.13 \mathrm{~V} \text { vs } \\
\mathrm{Ag} / \mathrm{AgCl} 1\end{array}$ & $\begin{array}{l}9.99 \times 10^{-7} \text { to } \\
3.21 \times 10^{-5} \mathrm{M} \\
9.43 \times 10^{-7} \text { to } \\
1.13 \times 10^{-5} \mathrm{M}\end{array}$ & $9.5 \times 10^{-8} \mathrm{M}$ & $\begin{array}{l}\text { citrus } \\
\text { fruits }\end{array}$ & $\begin{array}{l}\text { Oliveira } \\
\text { et al., } \\
2014 . \\
\\
\text { Ribeiro } \\
\text { et al., } \\
\text { 2014; }\end{array}$ \\
\hline Imidacloprid & I & $\begin{array}{l}\mathrm{NN} \\
\mathrm{C}\end{array}$ & BDDE & SWV & $\begin{array}{l}\mathrm{pH} 7 \\
0.05 \mathrm{M} \\
\text { sodium } \\
\text { sulfate }\end{array}$ & $\begin{array}{l}-1.21 \mathrm{~V} \text { vs } \\
\text { SCE }\end{array}$ & $\begin{array}{l}30 \text { to } 200 \\
\mathrm{mmo} / / \mathrm{L}\end{array}$ & $8.6 \mathrm{mmol} / \mathrm{L}$ & fruits & $\begin{array}{l}\text { Ben } \\
\text { Brahim } \\
\text { et al., } \\
2015 .\end{array}$ \\
\hline Isoprocarb & I & $\mathrm{CB}$ & GCE & I & $\begin{array}{c}\text { pH } 7 \\
\text { phosphate } \\
\text { buffer }\end{array}$ & $\begin{array}{l}1.4 \mathrm{~V} \mathrm{vs} \\
\mathrm{Ag} / \mathrm{AgCl}\end{array}$ & I & l & water & $\begin{array}{l}\text { Selva } \\
\text { et al., } \\
2017 \text {. }\end{array}$ \\
\hline Linuron & $\mathrm{H}$ & UR & $\begin{array}{l}\text { BDDE, } \\
\text { BDDE/PtNPs }\end{array}$ & DPV & $\begin{array}{c}\text { pH } 2 \\
\text { Britton-- } \\
\text { Robinson } \\
\text { buffer }\end{array}$ & $\begin{array}{l}1.29 \mathrm{~V} \mathrm{vs} \\
\mathrm{Ag} / \mathrm{AgCl}\end{array}$ & $\begin{array}{l}0.61 \text { to } 26 \\
\mu \mathrm{M} / \mathrm{L}\end{array}$ & $0.18 \mu \mathrm{M} / \mathrm{L}$ & water & $\begin{array}{l}\text { Figueiredo } \\
\text {-Filho } \\
\text { et al., } \\
2015 .\end{array}$ \\
\hline & & OPs & $\begin{array}{l}\mathrm{AChE} \\
/ \mathrm{Pin} 5 \mathrm{COOH} / \\
\mathrm{Fe}_{3} \mathrm{O}_{4} \mathrm{NP} / \mathrm{GCE}\end{array}$ & AMP & $\begin{array}{c}\text { pH } 7 \\
\text { phosphate } \\
\text { buffer }\end{array}$ & l & 0.1 to $60 \mathrm{nM}$ & $6.6 \mathrm{nM}$ & water & $\begin{array}{c}\text { Chauhan } \\
\text { et al., } \\
2015 .\end{array}$ \\
\hline IVIarationti & 1 & & $\begin{array}{l}\mathrm{NA} / \mathrm{AuNPs} / \mathrm{rGO} \\
-\mathrm{NH}_{2} / \\
\mathrm{AChE} / \mathrm{GCE}\end{array}$ & $\mathrm{CV}$ & $\begin{array}{c}\text { pH } 8 \\
\text { phosphate } \\
\text { buffer }\end{array}$ & $\begin{array}{l}0.7 \mathrm{~V} \text { vs } \\
\mathrm{Ag} / \mathrm{AgCl}\end{array}$ & $\begin{array}{l}0.0063 \text { to } \\
0.077 \mathrm{mg} / \mathrm{mL}\end{array}$ & $4.5 \mathrm{ng} / \mathrm{mL}$ & water & $\begin{array}{l}\text { Guler } \\
\text { et al., } \\
2017 .\end{array}$ \\
\hline Melamine & $\mathrm{H}$ & $\mathrm{TZ}$ & $\begin{array}{l}\text { MWCNTs- } \\
\text { HTPB-PABFC }\end{array}$ & SWV & $\begin{array}{c}\text { pH } 7 \\
\text { phosphate } \\
\text { buffer }\end{array}$ & $\begin{array}{l}0.8 \mathrm{~V} \text { vs } \\
\text { SCE }\end{array}$ & $\begin{array}{l}1 \times 10^{-3} \text { to } \\
1 \times 10^{-9} \mathrm{M}\end{array}$ & $\begin{array}{l}1.5 \times 10^{-7} \\
\mathrm{~mol} / \mathrm{L}\end{array}$ & $\begin{array}{l}\text { Pear, } \\
\text { apple, } \\
\text { cucum } \\
\text { ber }\end{array}$ & $\begin{array}{c}\text { Xu et al., } \\
2017 .\end{array}$ \\
\hline Methidathion & I & OPs & $\begin{array}{l}\mathrm{NA} / \mathrm{AuNPs} / \mathrm{rGO} \\
-\mathrm{NH}_{2} / \\
\mathrm{AChE} / \mathrm{GCE}\end{array}$ & $\mathrm{CV}$ & $\begin{array}{c}\text { pH } 8 \\
\text { phosphate } \\
\text { buffer }\end{array}$ & $\begin{array}{l}0.7 \mathrm{~V} \mathrm{vs} \\
\mathrm{Ag} / \mathrm{AgCl}\end{array}$ & $\begin{array}{l}0.012 \text { to } \\
0.105 \mathrm{mg} / \mathrm{mL}\end{array}$ & $9.5 \mathrm{ng} / \mathrm{mL}$ & water & $\begin{array}{l}\text { Guler et } \\
\text { al., } \\
2017 .\end{array}$ \\
\hline
\end{tabular}




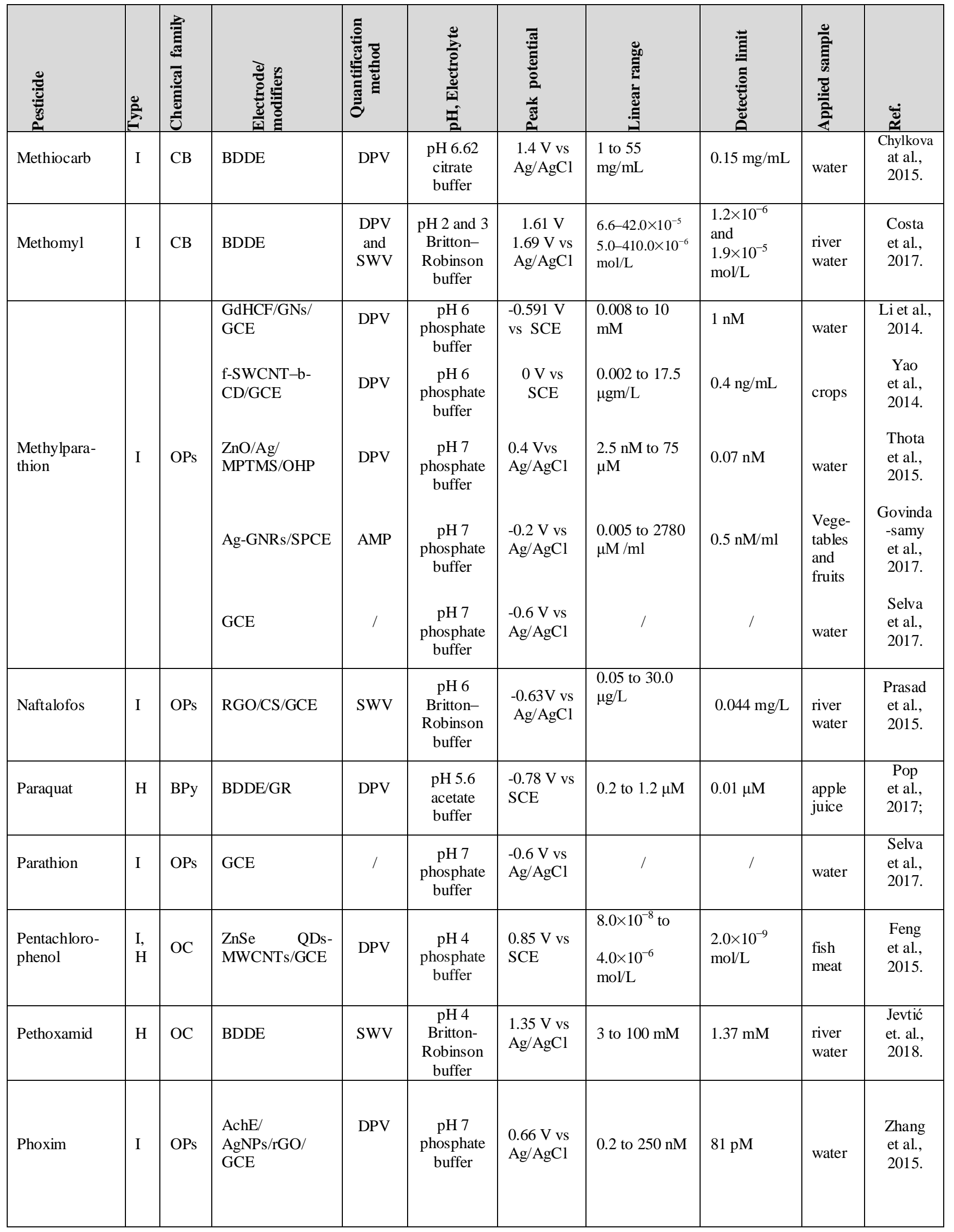




\begin{tabular}{|c|c|c|c|c|c|c|c|c|c|c|}
\hline 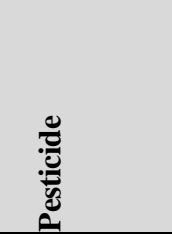 & 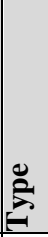 & 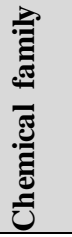 & 产 & 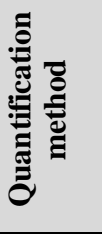 & 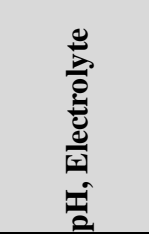 & 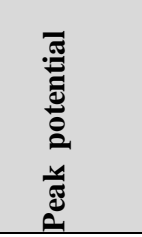 & 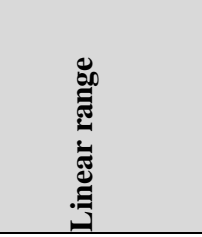 & 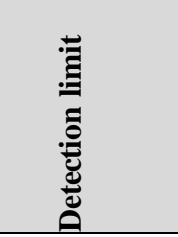 & 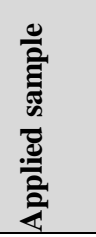 & 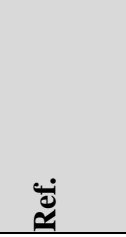 \\
\hline Propoxur & I & $\mathrm{CB}$ & $\begin{array}{l}\text { LACC-TYR- } \\
\text { AuNPs-CS/ } \\
\text { GPE } \\
\text { GCE }\end{array}$ & SWV & $\begin{array}{c}\text { pH } 5.5 \\
\text { Britton- } \\
\text { Robinson } \\
\text { buffer } \\
\text { pH } 7 \\
\text { phosphate } \\
\text { buffer }\end{array}$ & $\begin{array}{l}-0.2 \mathrm{~V} \mathrm{vs} \\
\mathrm{Ag} / \mathrm{AgCl} \\
\\
1.4 \mathrm{~V} \mathrm{vs} \\
\mathrm{Ag} / \mathrm{AgCl}\end{array}$ & $\begin{array}{l}4.99 \times 10^{-7} \text { to } \\
1.92 \times 10^{-5} \mathrm{M}\end{array}$ & $\begin{array}{l}1.87 \times 10^{-7} \\
\mathrm{M}\end{array}$ & $\begin{array}{l}\text { citrus } \\
\text { fruits }\end{array}$ & $\begin{array}{l}\text { Oliveira } \\
\text { et al., } \\
2014 \text {; } \\
\text { Selva } \\
\text { et al., } \\
2017 .\end{array}$ \\
\hline Pyrimethanil & $\mathrm{F}$ & $\mathrm{AP}$ & $\begin{array}{l}\text { MWCNTs- } \\
\text { IL/GCE }\end{array}$ & DPV & $\begin{array}{c}\text { pH } 6 \\
\text { phosphate } \\
\text { buffer }\end{array}$ & $\begin{array}{l}0.82 \mathrm{~V} \text { vs } \\
\text { SCE }\end{array}$ & $\begin{array}{l}1.0 \times 10^{-7} \text { to } \\
1.0 \times 10^{-4} \\
\mathrm{~mol} / \mathrm{L}\end{array}$ & $\begin{array}{l}1.6 \times 10^{-8} \\
\mathrm{~mol} / \mathrm{L}\end{array}$ & $\begin{array}{l}\text { orange } \\
\text { apple } \\
\text { water }\end{array}$ & $\begin{array}{l}\text { Yang } \\
\text { et al., } \\
2015 \text {. }\end{array}$ \\
\hline Thiodicarb & I & $\mathrm{CB}$ & MWCNT-PE & $\begin{array}{l}\text { DPV } \\
\text { and } \\
\text { AdSV }\end{array}$ & $\begin{array}{c}\mathrm{pH} 4 \\
\text { boric acid/ } \\
\text { citric acid/ } \\
\text { trisodium } \\
\text { orthophos } \\
\text { phate }\end{array}$ & $\begin{array}{r}-0.39 \mathrm{~V} \text { vs } \\
\mathrm{Ag} / \mathrm{AgCl}\end{array}$ & $10^{-5}$ to $10^{-10} \mathrm{M}$ & $1.07 \times 10^{-7} \mathrm{M}$ & soil & $\begin{array}{l}\text { Babu } \\
\text { et al., } \\
2014 \text {. }\end{array}$ \\
\hline Trichlorfon & I & OPs & $\begin{array}{l}\text { MWCNTs- } \\
\text { HTPB-PABFC }\end{array}$ & SWV & $\begin{array}{c}\text { pH } 7 \\
\text { phosphate } \\
\text { buffer }\end{array}$ & $\begin{array}{l}0.49 \mathrm{~V} \text { vs } \\
\text { SCE }\end{array}$ & $\begin{array}{l}1 \times 10^{-3} \text { to } \\
1 \times 10^{-9} \mathrm{M}\end{array}$ & $\begin{array}{l}3.5 \times 10^{-8} \\
\mathrm{~mol} / \mathrm{L}\end{array}$ & $\begin{array}{l}\text { pear } \\
\text { apple } \\
\text { cucu- } \\
\text { mber }\end{array}$ & $\begin{array}{c}\text { Xu et al., } \\
2017 .\end{array}$ \\
\hline Ziram & $\mathrm{F}$ & $\mathrm{CB}$ & $\begin{array}{l}\text { LACC-TYR- } \\
\text { AuNPs-CS/ } \\
\text { GPE }\end{array}$ & SWV & $\begin{array}{c}\text { pH } 5.5 \\
\text { Britton- } \\
\text { Robinson } \\
\text { buffer }\end{array}$ & $\begin{array}{l}-0.6 \mathrm{~V} \text { vs } \\
\mathrm{Ag} / \mathrm{AgCl}\end{array}$ & $\begin{array}{l}4.99 \times 10^{-7} \text { to } \\
1.92 \times 10^{-5}\end{array}$ & $1.87 \times 10^{-7} \mathrm{M}$ & $\begin{array}{l}\text { citrus } \\
\text { fruits }\end{array}$ & $\begin{array}{c}\text { Oliveira } \\
\text { et al., } \\
2014 .\end{array}$ \\
\hline
\end{tabular}

Pesticide types: F - fungicide; H - herbicide; I - insecticide; Chemical family: AP - anilinopyrimidine; BI - benzimidazole; BPy bipyridilium; CB - carbamates; ISD - isoxazolidinone; NA - nitroaniline; NNC - neonicotinoid; NP - nitropesticides; OC organochlorines; OPs - organophosphate; TDZ - tiadizine; TZ - triazine; UR-urea pesticide. Electrode/ modifiers: AChE acetylcholinesterase; AgNPs - silver nanoparticles; AuNPs - goldcnanoparticles; BDDE - boron-doped diamond electrode; CA cellulose acetate; GA - glutaraldehyde; chl-Ab - chlorpyrifos antibodies; CNS - carbon nanosphere; CoPc-AQ- cobalt phthalocyanineanthraquinone hybrid; $\mathrm{CPE}$ - carbon paste electrode; $\mathrm{CS}$ - chitosan; $\mathrm{CuO} \mathrm{NFs} \mathrm{-} \mathrm{copper} \mathrm{oxide} \mathrm{nanoflowers;} \mathrm{Fe}_{3} \mathrm{O}_{4} \mathrm{NP}_{-}$ iron oxide nanoparticles; f-SWCNT-b-CD - carboxylic acid-functionalized single-walled carbon nanotubes-b-cyclodextrin; FTO fluorine doped tin-oxide; GCE - glassy carbon electrode; GdHCF - gadolinium hexacyanoferrate; GE -gold electrode; GNRs graphene nanoribbons film; GNs - graphene nanosheets; GPE - graphene doped carbon paste electrode; GR - graphene; HTPB hydroxyl-terminated polybutadiene; IL - ionic liquids; ITO - indium tin oxide; LACC - laccase; LB - Langmuir-Blodgett monolayer film; MIP - molecularly imprinted polymer; MPTMS - mercaptopropyltrimethoxysilane layers; MWCNT - multiwalled carbon nanotubes; NA - nafion; OHP - overhead projector films; PABFC - poly 4-acryloyloxybutyl(ethyl) ferrocene carboxylates; Pin5COOH - poly(indole-5-carboxylic acid); RGO - reduced graphene oxide; rGO- $\mathrm{NH}_{2}$ - amine functionalized reduced graphene oxide; SPCE - screen printed carbon electrode; SWCNTs - single walled carbon nanotubes; TYR - tyrosinase; ZnSe QDs - ZnSe quantum dots; $\mathrm{ZrO}_{2}$ - zirconium oxide. Quantification methods: AMP - amperometry; CV- cyclic voltammetry; DP-AdSV differential pulse adsorptive stripping voltammetry; DPV - differential pulse voltammetry; POT potenciometry; SWV- square wave voltammetry.

In addition, it has the widest potental "window" (from -2V to $2 \mathrm{~V}$ ) of all reported electrodes, a small basic current, a large overvoltage in the separation of hydrogen and oxygen, and good mechanical performance (Uslu \& Ozkan, 2007.). Jevtić et al., 2018a. applied BDDE for the determination of bentazone herbicide in river waters with significant advantages in terms of

speed, sensitivity, simplicity, repeatability and efficiency compared to previously reported procedures for its quantification. The sensitivity of the method is 0.5. The electrochemical reduction of imidacloprid insecticide on BDDE was first performed by Benbrahim et al. 2015. The quantification was efficiently executed by SWV in fruit with high accuracy and

\section{CHEMISTRY}


precision. The first data on the electrochemical behavior of pentoxamid were given by Jevtić et al. 2018 b. The assay was carried out in Britton-Robinson buffer at $\mathrm{pH} 4$ and the result was an anode peak at $1.35 \mathrm{~V}$ vs reference $\mathrm{Ag} / \mathrm{AgCl}$ electrode. With a detection limit of $1.37 \mu \mathrm{M}$ this method is proposed as a fast, cheaper and simpler alternative to conventional chromatography. A similar situation exists in the case of detection of metiocarb with a detection limit of $0.15 \mathrm{mg} / \mathrm{ml}$ (Chylkova et al., 2015.), methomyl in commercial products and water with a detection limit of $1.2 \times 10^{-6} \mathrm{~mol} / \mathrm{L}$ (Costa et al ., 2017.) and clomazone in surface waters with a detection limit of $0.2 \mu \mathrm{M}$ (Djurdjić et al., 2018.).

\section{ELECTRODE MODIFIERS}

\section{Nanomaterials}

Intensive efforts to improve selectivity and sensitivity in determining the most serious pesticide pollutants today have led to the mass introduction of nanomaterials in electrochemistry (Govindhan et al., 2014.). The International Organization for Standardization of Nanomaterials defines them as materials whose particles are between 1 and $100 \mathrm{~nm}$. In combination with modern electrochemical techniques, they are a very effective instrument for controlling pollution due to significant advantages such as effective catalysis, rapid mass transport and large surface area (Saini et al., 2017.). Nanomaterials that have been used in the target period as modifiers are discussed below, and their connection with the electrodes on which they are applied and numerous other data are given in Table 1. As it can be seen, carbon materials were extensively used as electrode materials and also as electrode modifiers. Structures of mentioned carbon materials were presented in Figure 2.

\section{Carbon nanotubes (CNTs)}

Carbon nanotubes exist in the form of single-walled nanotubes that contain one layer of graphene curved in the tube (SWNTs) and multi-walled nanotubes containing several layers in the form of tubes concentrated around the same axis (MWNTs). They are characterized by good conductivity, stability, flexibility and reactivity. Despite the difficulties in isolating single-walled nanotubes, their application was reported in the analysis of chlorpyrifos, insecticides from the organophosphate group, with a detection limit of $70 \mathrm{pg} / \mathrm{ml}$ under optimal conditions. They are applied in combination with copper-oxide nanoparticles to GCE. The sensor is easily regenerated by urea and allows detection of this pesticide with excellent selectivity (Xu G. et al., 2017.). In combination with cyclodextrin, the GC nanoparticles were applied for the purpose of analyzing methyl parathion in plant specimens where a detection limit of $0.4 \mathrm{ng} / \mathrm{ml}$ was reached (Yao et al., 2014.).
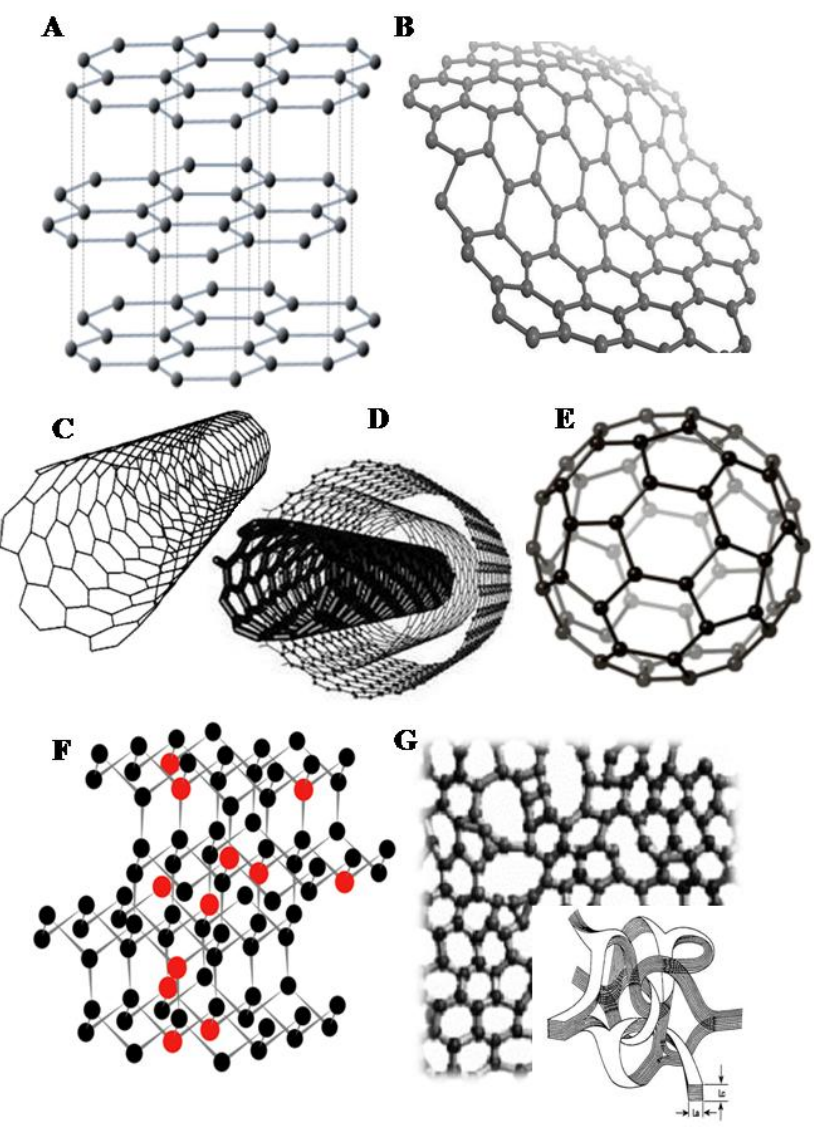

Fig. 2. Carbon material used as electrode materials and modifiers: A) graphite, B) graphene, C) single-walled carbon nanotubes, D) multi- walled carbon nanotubes, E) fullerene, F) boron-doped diamond and G) glassy carbon.

\section{Graphene}

Graphene, either in its basic form or in the form of oxide or reduced oxide, possesses unique physico-chemical properties very suitable for use, among others in electrochemistry (Zeng et al., 2016.). The reported case of BDDE modification by graphene led to significantly enhanced pixel intensity in relation to the application of an unmodified electrode. Simultaneous detection of pesticide paraquat and carbaryl in apple juice was performed by DPV technique with a detection limit of $0.01 \mu \mathrm{M}$ and $0.07 \mu \mathrm{M}$ respectively. (Pop et al., 2017.). Prasad et al., 2015. determined dimethylvinphos and naphthalofos using GCE modified reduced graphene oxide and ciosane. The electrochemical response was significantly better than that without the presence of graphene derivative, which was explained by the strong absorption of targeted pesticides on the film of the modifier, and due to its excellent conductivity. The large surface area significantly improved the sensitivity of the method. Graphene-oxide nanotubes are not as popular as other graphene derivatives, but were successfully applied in combination with silver particles and screen printed technology for methyl paration detection. The electrocatalytic ability of 
silver in combination with the good properties of these nanotubes (good conductivity, large contact surface and catalytic capacities) make this sensor very suitable for the detection of the mentioned pesticide in fruit and vegetables with a detection limit of $0.5 \mathrm{nM}$ (Govindasamy et al., 2017.).

\section{Fullerene}

The behavior of graphene and carbon nanotubes is very similar to the behavior of fullerene, the difference lies in the larger surface of the graphene due to its one-layer structure. In spite of that, the chemical activity of the graphene is lower than the indicated fullerene (Chehimi \& Pinson 2013.). Fullerene, in combination with multidisciplinary nanoparticles and nafion, was used to detect carbendazim fungicide from benzimidazole with a detection limit of $10^{-8} \mathrm{~mol} / \mathrm{L}$. (Teadoum et al., 2016.).

\section{Biocomponents and Metal nanoparticles}

The biosensors for detection of pesticides function on the principle of loss of activity of the biocomponent due to the smallest amount of highly toxic pesticides, or on the direct interaction of biocomponents with targeted analytes (Sassolas et al., 2012.). In past five years, the most commonly used biocomponent in biosensors for pesticide analysis is the acetylcholinesterase enzyme, and in almost all cases it is applied in combination with some nanoparticles. Zhang et al., 2015. determined pesticide phoxim using a combination of acetylcholinesterase, gold nanoparticles and reduced graphene oxide. Acetylcholinesterase, in normal conditions, naturally accelerates the decomposition of acetylcholine chloride to thiocholine, which is electro-active. Reduction of this electroactivity in electrochemical measurements is proportional to the presence of phoxim. On this principle, its application in combination with $\mathrm{Fe}_{3} \mathrm{O}_{4}$ NPs for the amperometric detection of chlorpyrifos which reach LOD of $9.1 \mathrm{nM}$. (Chauhan et al., 2015.), and in combination with carbon nanoferms for the detection of carbofuran and phenitrothion (Cai et al., 2014.), was presented. Laccase and tyrosinase enzymes for voltammetric detection of ziram, propoxur, carbaryl and formetanates were used together with golden nanoparticles and cytosan. The sensor shows better characteristics in the presence of both enzymes, compared to the presence of only one of them. The reason for this synergy effect is a stronger flow of electricity due to their simultaneous catalytic action on phenol compounds (Oliveira et al., 2014.).

As can be seen, from metal nanoparticles, lately, the gold nanoparticles have undoubtedly been the most popular. Althought gold is considered to be an inert material in redox exchanges, in nano scale it becomes an excellent component for making chemical and biological sensors (Tang \& Tang 2015.). Guler et al., 2017. used these nanoparticles in combination with reduced graphene oxide, naphion and enzyme acetylcholinesterase for the detection of chlorpyrifos, malathion and methidathion, and in a similar combinations, without nafion the insecticide proxima was also selected (Zhang et al., 2015.). Fluorine doped tin oxide, chlorpyrifos antibodies, and gold nanoparticles are the combination for detection of chlorpyrifos with a detection limit of $10 \mu \mathrm{M}$ (Gandhi et al., 2018.).

Cytosan is one of the most commonly used natural polymers. Its presence provides a suitable biocompatible environment for enzymes. It is also easily formed into films or any other form (Arduini et al., 2016). With the reduced graphene oxide on GC electrode it was used to detect naphthalofos and dimethylvinphos by a group of researchers, Prasad et al., 2015

The exceptional specificity of the antigen-antibody interaction found its place in electrochemistry. Liu et al., 2014. determined atrazines with a combination of anti-atrazine with gold nanoparticles applied to the gold electrode with a detection limit of $0.016 \mathrm{ng} / \mathrm{mL}$. With fluorine-doped tin oxide (FTO) and gold nanoparticles, anti-chlorpyrifos antibodies for the detection of chlorpyrifos were combined. (Gandhi et al., 2018.). The FTO has the role of a modifier carrier on gold or carbon-based electrodes.

\section{CONCLUSION}

A literature review brings us to a conclusion that electrochemical techniques have a good chance of replacing conventional chromatographic pesticide quantification in future. Cyclic voltammetry remains an indispensable instrument for observing reaction mechanisms, while amperometry, and especially pulse methods, are applied to achieve as low as possible detection limits. The sensitivity and selectivity of the products from year to year are getting better owing to the use of electrodes of various performances additionally enhanced by modification using different materials. In this field, the popularity of nano-sized materials, especially those based on carbon, is evident. The use of biomaterials, enzymes and antibodies, as well as combinations of biomaterials and nanoparticles, also greatly contributed to the improvement of the techniques.

In the future, the goals are in speed simplifying and speeding up the method, lowering the detection limits, increaseing selectivity and, in view of the nature of pesticide contamination, finding a suitable way to monitor them on the ground in all conditions and real samples. Different combinations of electrochemical techniques, electrode materials, modifiers, and production techniques, miniaturization due to construction of microelectrodes, taking the best of all, almost certainly prove that these goals of application of electroanalytical methods in pesticide control are highly achievable.

\section{ACKNOWLEGMENTS}

Financial support for this study was granted by the Ministry of Science and Technological Development of the Republic of Serbia, Project Number III45022.

\section{CHEMISTRY}




\section{REFERENCES}

Arduini, F., Cinti, S., Scognamiglio, V., \& Moscone, D. 2016. Nanomaterials in electrochemical biosensors for pesticide detection: advances and challenges in food analysis. Microchimica Acta, 183(7), pp. 2063-2083. doi:10.1007/s00604-016-1858-8

Babu, T. R., Reddy, S. R., \& Sujana, P. 2014. Comparative voltammetric study and determination of carbamate pesticide residues in soil at carbon nanotubes paste electrodes. Journal of Electrochemical Science and Engineering, doi:10.5599/jese.2013.0041

Bakirhan, N. K., Uslu, B., \& Ozkan, S. A. 2018. Food Safety and Preservation. Netherlands: Elsevier.

Ben, B. M., Belhadj, A. H., Abdelhédi, R., \& Samet, Y. 2016. Electrochemical behavior and analytical detection of Imidacloprid insecticide on a BDD electrode using squarewave voltammetric method. Chinese Chemical Letters, 27(5), pp. 666-672. doi:10.1016/j.cclet.2015.12.032

Cai, J., Zhou, L., \& Han, E. 2014. A Sensitive Amperometric Acetylcholine Biosensor Based on Carbon Nanosphere and Acetylcholinesterase Modified Electrode for Detection of Pesticide Residues. Analytical Sciences, 30(6), pp. 669-673. doi:10.2116/analsci.30.669

Chauhan, N., Narang, J., \& Jain, U. 2016. Amperometric acetylcholinesterase biosensor for pesticides monitoring utilising iron oxide nanoparticles and poly(indole-5carboxylic acid).Journal of Experimental Nanoscience, 11(2), pp. 111-122. doi:10.1080/17458080.2015.1030712

Chehimi, M. M., \& Pinson, J. 2013. Applied surface chemistry of nanomaterials. New York: Nova publishers.

Chýlková, J., Tomášková, M., Švancara, I., Janíková, L., \& Šelešovská, R. 2015. Determination of methiocarb pesticide using differential pulse voltammetry with a boron-doped diamond electrode. Analytical Methods, 7(11), pp. 46714677. doi:10.1039/c5ay00979k

Costa, D. J. E., Santos, J. C. S., Sanches-Brandão, F. A. C., Ribeiro, W. F., Salazar-Banda, G. R., \& Araujo, M. C. U. 2017. Boron-doped diamond electrode acting as a voltammetric sensor for the detection of methomyl pesticide. Journal of Electroanalytical Chemistry, 789, pp. 100-107. doi:10.1016/j.jelechem.2017.02.036

Damalas, C. A. 2009. Understanding benefits and risks of pesticide use. review. Scientific Research and Essay, 4(10), pp. 945-949.

Djurdjić, S., Vukojević, V., Jevtić, S., Pergal, M. V., Petković, B. B., \& Stanković, D. M. 2018. Herbicide Clomazone Detection Using Electroanalytical Approach Using Boron Doped. Int. J. Electrochem. Sci. . Diamond Electrode. Int. J. Electrochem. Sci., 13, pp. 2791 - 2799. doi: 10.20964/2018.03.39

Feng, S., Yang, R., Ding, X., Li, J., Guo, C., \& Qu, L. 2015. Sensitive electrochemical sensor for the determination of pentachlorophenol in fish meat based on $\mathrm{ZnSe}$ quantum dots decorated multiwall carbon nanotubes nanocomposite.
Ionics, 21(12), pp. 3257-3266. doi:10.1007/s11581-0151512-1

Figueiredo-Filho, L. C. S., Sartori, E. R., \& Fatibello-Filho, O. 2015. Electroanalytical determination of the linuron herbicide using a cathodically pretreated boron-doped diamond electrode: comparison with a boron-doped diamond electrode modified with platinum nanoparticles. Analytical Methods, 7(2), pp. 643-649. doi:10.1039/c4ay02182g

Fischer, J., Dejmkova, H., \& Barek, J. 2011. Electrochemistry of Pesticides and its Analytical Applications. Current Organic Chemistry, 15(17), pp. 2923-2935. doi:10.2174/138527211798357146

Gothwal, A., Beniwal, P., Dhull, V., \& Hooda, V. 2014. Preparation of Electrochemical Biosensor for Detection of Organophosphorus Pesticides. International Journal of Analytical Chemistry, 2014, pp. 1-8. doi:10.1155/2014/303641

Govindasamy, M., Mani, V., Chen, S., Chen, T., \& Sundramoorthy, A.K. 2017. Methyl parathion detection in vegetables and fruits using silver@graphene nanoribbons nanocomposite modified screen printed electrode. Scientific Reports, 7(1). doi:10.1038/srep46471

Guler, M., Turkoglu, V., \& Basi, Z. 2017. Determination of malation, methidathion, and chlorpyrifos ethyl pesticides using acetylcholinesterase biosensor based on Nafion/Ag@rGO-NH2 nanocomposites. Electrochimica Acta, 240, pp. 129-135. doi:10.1016/j.electacta.2017.04.069

Hassani, S., Momtaz, S., Vakhshiteh, F., Maghsoudi, A. S., Ganjali, M. R., Norouzi, P., \& Abdollahi, M. 2017. Biosensors and their applications in detection of organophosphorus pesticides in the environment. Archives of Toxicology, 91(1), pp. 109-130. doi:10.1007/s00204-016$1875-8$

İpek, Y., Şener, M. K., \& Koca, A. 2015. Electrochemical pesticide sensor based on Langmuir-Blodgett film of cobalt phthalocyanine-anthraquinone hybrid. Journal of Porphyrins and Phthalocyanines, 19(05), pp. 708-718. doi:10.1142/s1088424615500182

Irandoust, M., \& Haghighi, M. 2016. Electrochemical Study and Determination of Dinitramine Using Glassy Carbon Electrodes Modified with Multi-walled Carbon Nanotubes. Electrochemistry, 84(4), pp. 228-233. doi:10.5796/electrochemistry.84.228

Jevtić, S., Stefanović, A., Stanković, D. M., Pergal, M. V., Ivanović, A. T., Jokić, A., \& Petković, B. B. 2018. Borondoped diamond electrode - A prestigious unmodified carbon electrode for simple and fast determination of bentazone in river water samples. Diamond and Related Materials, 81, pp. 133-137. doi:10.1016/j.diamond.2017.12.009

Jevtić, S., Vukojević, V., Djurdjić, S., Pergal, M. V., Manojlović, D. D., Petković, B. B., \& Stanković, D. M. 2018. First electrochemistry of herbicide pethoxamid and its quantification using electroanalytical approach from mixed commercial product. Electrochimica Acta, 277, pp. 136-142. doi:10.1016/j.electacta.2018.05.004 
Jokanović, V. 2013. Nanomedicina - najveći izazov 21. veka. Beograd: Data status.

Khadem, M., Faridbod, F., Norouzi, P., Foroushani, A. R., Ganjali, M. R., \& Shahtaheri, S. J. 2016. Biomimetic electrochemical sensor based on molecularly imprinted polymer for dicloran pesticide determination in biological and environmental samples. Journal of the Iranian Chemical Society, 13(11), pp. 2077-2084. doi:10.1007/s13738-0160925-8

Li, Y., Xu, M., Li, P., Dong, J., \& Ai, S. 2014. Nonenzymatic sensing of methyl parathion based on graphene/gadolinium Prussian Blue analogue nanocomposite modified glassy carbon electrode. Analytical Methods, 6(7), p. 2157. doi:10.1039/c3ay41820k

Liang, H. C., Bilon, N., \& Hay, M. T. 2014. Analytical Methods for Pesticide Residues. Water Environment Research, 86(10), pp. 2132-2155. doi:10.2175/106143014x13975035526185

Liu, X., Li, W., Li, L., Yang, Y., Mao, L., \& Peng, Z. 2014. A label-free electrochemical immunosensor based on gold nanoparticles for direct detection of atrazine. Sensors and Actuators B: Chemical, 191, pp. 408-414. doi:10.1016/j.snb.2013.10.033

Mashuni, Ramadhan, L. O. A. N., Jahiding, M., \& Herniati, 2016. Analysis of diazinon pesticide using potentiometric biosensor based on enzyme immobilized cellulose acetate membrane in gold electrode. IOP Conference Series: Materials Science and Engineering, 107, p. 12013. doi:10.1088/1757-899x/107/1/012013

Melo, L. C., Julião, M. S. S., Milhome, M. A. L., do Nascimento, R. F., De, S. D., de Lima-Neto, P., \& Correia, A. N. 2018. Square Wave Adsorptive Stripping Voltammetry Determination of Chlorpyriphos in Irrigation Agricultural Water. Journal of Analytical Chemistry, 73(7), pp. 695-704. doi:10.1134/s1061934818070109

Mogha, N. K., Sahu, V., Sharma, M., Sharma, R. K., \& Masram, D. T. 2016. Biocompatible $\mathrm{ZrO} 2$ - reduced graphene oxide immobilized AChE biosensor for chlorpyrifos detection. Materials \& Design, 111, pp. 312-320. doi:10.1016/j.matdes.2016.09.019

Mostafa, G. 2010. Electrochemical Biosensors for the Detection of Pesticides. The Open Electrochemistry Journal, 2(1), pp. 22-42. doi: 10.2174/1876505x01002010022

Navaratne, A., \& Priyanth, N. 2011. Chemically Modified Electrodes for Detection of Pesticides. In M. Stoytcheva Ed., Pesticides in the Modern World - Trends in Pesticides Analysis.IntechOpen. doi:10.5772/17320

Ni, Y., Qiu, P., \& Kokot, S. 2005. Simultaneous voltammetric determination of four carbamate pesticides with the use of chemometrics. Analytica Chimica Acta, 537(1-2), pp. 321330. doi:10.1016/j.aca.2004.12.080

Oliveira, T. M. B. F., Barroso, M. F., Morais, S., Araujo, M., Freire, C., Lima-Neto, P., Correia, A.N., Oliveira, M. B. P. P., \& Delerue-Matos, C. 2014. Sensitive bi-enzymatic biosensor based on polyphenoloxidases-gold nanoparticleschitosan hybrid film-graphene doped carbon paste electrode for carbamates detection. Bioelectrochemistry, 98, pp. 20-29. doi:10.1016/j.bioelechem.2014.02.003

-Population Division Department of Economic and Social Affairs United Nations Secretariat. . The World at Six Billion. http://mysite.du.edu/ rkuhn/ints4465/world-at-sixbillion.pdf.

Pop, A., Manea, F., Flueras, A., \& Schoonman, J. 2017. Simultaneous Voltammetric Detection of Carbaryl and Paraquat Pesticides on Graphene-Modified Boron-Doped Diamond Electrode. Sensors, 17(9), p. 2033. doi:10.3390/s17092033

Reddy, P. P., Ofamaja, A. E., Reddy, C. N., \& Naido, E. B. 2016. Square Wave Voltammetric Detection of Dimethylvinphos and Naftalofos in Food and Environmental Samples Using RGO/CS modified Glassy Carbon Electrode. Int. J. Electrochem. Sci, 11, pp. 65-79.

Ribeiro, F. W. P., Barroso, M. F., Morais, S., Viswanathan, S., Lima-Neto, P., Correia, A. N., Oliveira, M. B. P. P., \& Delerue-Matos, C. 2014. Simple laccase-based biosensor for formetanate hydrochloride quantification in fruits. Bioelectrochemistry, 95, pp. 7-14. doi:10.1016/j.bioelechem.2013.09.005

Sanford, C., Sabapathy, D., Morrison, H., \& Gaudreau, K. 2015. Systematic Review. In Pesticides and human health. Prince Edward Island, Canada. Part 1.

Sanghavi, B. J., Wolfbeis, O. S., Hirsch, T., \& Swami, N. S. 2015. Nanomaterial-based electrochemical sensing of neurological drugs and neurotransmitters. Microchimica Acta, 182(1-2), pp. 1-41. doi:10.1007/s00604-014-1308-4

Sani, R. K., Bagri, L. P., \& Bajpai, A. K. 2017. New Pesticides and Soil Sensors. Netherlands: Elsevier. chapter 14.

Sassolas, A., Prieto-Simón, B., \& Marty, J. 2012. Biosensors for Pesticide Detection: New Trends. American Journal of Analytical Chemistry, 03(03), pp. 210-232. doi:10.4236/ajac.2012.33030

Selva, T. M. G., Araujo, W. R., \& Paixao, T. R. L. C. 2017. Electrochemical sensor for discrimination of carbamates and organophosphorus pesticides. In 2017 ISOCS/IEEE International Symposium on Olfaction and Electronic Nose (ISOEN).Institute of Electrical and Electronics Engineers (IEEE), pp. 1-3. doi:10.1109/isoen.2017.7968922

Shahtaheri, S. J., Faridbod, F., \& Khadem, M. 2017. Highly Selective Voltammetric Sensor Based on Molecularly Imprinted Polymer and Carbon Nanotubes to Determine the Dicloran Pesticide in Biological and Environmental Samples. Procedia Technology, 27, pp. 96-97. doi:10.1016/j.protcy.2017.04.041

Skoog, D. A., Holler, F. J., \& Nieman, A. T. 1997. Principles of instrumental analysis. Unite States of America: Books/Cole. fifth edition.

Talan, A., Mishra, A., Eremin, S. A., Narang, J., Kumar, A., \& Gandhi, S. 2018. Ultrasensitive electrochemical immunosensing platform based on gold nanoparticles triggering chlorpyrifos detection in fruits and vegetables. Biosensors and Bioelectronics, 105, pp. 14-21. doi:10.1016/j.bios.2018.01.013 
Tago, D., Andersson, H., \& Treich, N. 2014. Pesticides and Health: A Review of Evidence on Health Effects, Valuation of Risks, and Benefit-Cost Analysis. In G. C. Blomquist\& K. Bolin Eds., Adv Health Econ Health Serv Res.Emerald., pp. 203-295. doi:10.1108/s0731-2199_2014_0000024006

Tang, J., \& Tang, D. 2015. Non-enzymatic electrochemical immunoassay using noble metal nanoparticles: a review. Microchimica Acta, 182(13-14), pp. 2077-2089. doi:10.1007/s00604-015-1567-8

Teadoum, D. N., Noumbo, S. K., Arnaud, K. T., Ranil, T. T., Mvondo, Z. A. D., \& Tonle, I.K. 2016. Square Wave Voltammetric Determination of Residues of Carbendazim Using a Fullerene/Multiwalled Carbon Nanotubes/Nafion//Coated Glassy Carbon Electrode. International Journal of Electrochemistry, 2016, pp. 1-9. doi:10.1155/2016/7839708

Thota, R., \& Ganesh, V. 2016. Selective and sensitive electrochemical detection of methyl parathion using chemically modified overhead projector sheets as flexible electrodes. Sensors and Actuators B: Chemical, 227, pp. 169177. doi:10.1016/j.snb.2015.12.008

Tonle, I., \& Ngameni, E. 2011. Voltammetric Analysis of Pesticides. In M. Stoytcheva Ed., Pesticides in the Modern World - Trends in Pesticides Analysis.IntechOpen. doi: $10.5772 / 18623$

Uslu, B., \& Ozkan, S. 2007. Electroanalytical Application of Carbon Based Electrodes to the Pharmaceuticals. Analytical Letters, 40(5), pp.

817-853. doi:10.1080/00032710701242121

Vukojević, V., Djurdjić, S., Jevtić, S., Pergal, M., Marković, A., Mutić, J., Petković, B. B. \& Stanković D. M. 2018. First electrochemical investigation of organophosphorus pesticide azametiphos and its quantification using electroanalytical approach. International Journal of Environmental Analytical
Chemistry, 98(13), pp.

$1175-1185$. doi:10.1080/03067319.2018.1537394

Xu, F., Cui, Z., Li, H., \& Luo, Y. 2017. Electrochemical determination of trace pesticide residues based on multiwalled carbon nanotube grafted acryloyloxy ferrocene carboxylates with different spacers. RSC Advances, 7(12), pp. 7431-7441. doi:10.1039/c6ra26436k

Xu, G., Huo, D., Hou, C., Zhao, Y., Bao, J., Yang, M., \& Fa, H. 2018. A regenerative and selective electrochemical aptasensor based on copper oxide nanoflowers-single walled carbon nanotubes nanocomposite for chlorpyrifos detection. Talanta, 178, pp. 1046-1052. doi:10.1016/j.talanta.2017.08.086

Yang, J., Wang, Q., Zhang, M., Zhang, S., \& Zhang, L. 2015. An electrochemical fungicide pyrimethanil sensor based on carbon nanotubes/ionic-liquid construction modified electrode. Food Chemistry, 187, pp. 1-6. doi:10.1016/j.foodchem.2015.04.009

Yao, Y., Zhang, L., Xu, J., Wang, X., Duan, X., \& Wen, Y. 2014. Rapid and sensitive stripping voltammetric analysis of methyl parathion in vegetable samples at carboxylic acidfunctionalized SWCNTs- $\beta$-cyclodextrin modified electrode. Journal of Electroanalytical Chemistry, 713, pp. 18. doi:10.1016/j.jelechem.2013.11.024

Zeng, Y., Zhu, Z., Du, D., \& Lin, Y. 2016. Nanomaterial-based electrochemical biosensors for food safety. Journal of Electroanalytical Chemistry, 781, pp. 147-154. doi:10.1016/j.jelechem.2016.10.030

Zhang, Y., Liu, H., Yang, Z., Ji, S., Wang, J., Pang, P., Feng, L., Wang, H., Wu, Z., \& Yang, W. 2015. An acetylcholinesterase inhibition biosensor based on a reduced graphene oxide/silver nanocluster/chitosan nanocomposite for detection of organophosphorus pesticides. Analytical Methods, 7(15), pp. 6213-6219. doi:10.1039/c5ay01439e 